\title{
Genetics, cognition, and neurobiology of schizotypal personality: a review of the overlap with schizophrenia
}

\author{
Ulrich Ettinger ${ }^{1}{ }^{*}$, Inga Meyhöfer ${ }^{1}$, Maria Steffens ${ }^{1}$, Michael Wagner ${ }^{2}$ and Nikolaos Koutsouleris ${ }^{3}$ \\ ${ }^{1}$ Department of Psychology, University of Bonn, Bonn, Germany \\ ${ }^{2}$ Department of Psychiatry and Psychotherapy, University of Bonn, Bonn, Germany \\ ${ }^{3}$ Department of Psychiatry and Psychotherapy, University of Munich, Munich, Germany
}

\section{Edited by:}

Neeltje E. M. Van Haren, University

Medical Centre Utrecht, Netherlands

\section{Reviewed by:}

Hubertus Axer, Jena University

Hospital, Germany

Drozdstoy Stoyanov Stoyanov,

Medical University, Bulgaria

*Correspondence:

Ulrich Ettinger, Department of Psychology, University of Bonn, Kaiser-Karl-Ring 9, 53111 Bonn, Germany

e-mail: ulrich.ettinger@uni-bonn.de
Schizotypy refers to a set of temporally stable traits that are observed in the general population and that resemble the signs and symptoms of schizophrenia. Here, we review evidence from studies on genetics, cognition, perception, motor and oculomotor control, brain structure, brain function, and psychopharmacology in schizotypy. We specifically focused on identifying areas of overlap between schizotypy and schizophrenia. Evidence was corroborated that significant overlap exists between the two, covering the behavioral brain structural and functional as well molecular levels. In particular, several studies showed that individuals with high levels of schizotypal traits exhibit alterations in neurocognitive task performance and underlying brain function similar to the deficits seen in patients with schizophrenia. Studies of brain structure have shown both volume reductions and increase in schizotypy, pointing to schizophrenia-like deficits as well as possible protective or compensatory mechanisms. Experimental pharmacological studies have shown that high levels of schizotypy are associated with (i) enhanced dopaminergic response in striatum following administration of amphetamine and (ii) improvement of cognitive performance following administration of antipsychotic compounds. Together, this body of work suggests that schizotypy shows overlap with schizophrenia across multiple behavioral and neurobiological domains, suggesting that the study of schizotypal traits may be useful in improving our understanding of the etiology of schizophrenia.

Keywords: schizophrenia, schizotypy, personality, phenotype, spectrum, genetics, neuroimaging, cognition

\section{INTRODUCTION}

Schizophrenia is a serious psychiatric condition with unknown etiology characterized by positive symptoms (such as hallucinations and delusions), negative symptoms (such as avolition and psychomotor poverty), and thought disorder as well as cognitive deficits. The illness has adverse consequences not only for the sufferers but also their relatives and society at large (1). Patients with schizophrenia are at significantly increased risk of suicide and frequently suffer socio-economic disadvantages. The costs to society include direct costs, such as treatment, as well as indirect costs, such as loss of manpower at work due to the illness or due to caring by relatives $(2,3)$. Current pharmacological treatments of schizophrenia are successful at reducing psychotic symptoms but do not provide a cure (4), especially given that neurocognitive deficits and negative symptoms appear less amenable to treatment than psychotic phases of the disorder.

An important step in advancing etiological research into this condition was the realization that schizophrenia is not, despite its clinically important and reliable categorical diagnosis according to the International Classification of Disease (ICD) of the World Health Organization or the Diagnostic and Statistical Manual (DSM) of the American Psychiatric Association, a binary phenotype (present, absent) with sudden disease onset. Instead, there is substantial agreement amongst clinicians and researchers that the systematic investigation of intra- and inter-individual continua plays an important role in improving our understanding of the etiology of the disorder (5-7).

There are at least three different types of continua to be distinguished in this context: first, retrospective and longitudinal studies have provided evidence for a temporal continuum. For example, early motor and cognitive deficits as well as individual psychotic symptoms are observed in childhood and youth of those who later develop schizophrenia $(8,9)$. These signs and symptoms dramatically increase in the prodrome, immediately before illness onset (10).

Second, clinical studies of patients with schizophrenia have shown that even within the clinically meaningful diagnostic borders of schizophrenia, significant inter-individual differences exist both in the kind and severity of symptoms as well as in the longitudinal course of the illness. In an influential study, Strauss (11) observed in a sample of patients that symptoms such as hallucinations or delusions could often not be classified as unambiguously present or absent. This observation was interpreted as a contradiction to the assumption of a binary illness phenotype [(11); p. 585]: "Hallucinations and delusions are key symptoms in the conceptualization and diagnosis of schizophrenia. In the past, their definition as discrete symptoms has been used to substantiate the supposedly discrete nature of this disorder. Recognizing these symptoms as points on continua implies that schizophrenia 
too might be more adequately described as a point or a series of points on a functional continuum."

Third, and of most relevance to this article, a large and continuously growing body of evidence suggests that certain aspects of the phenomenology of schizophrenia are also traceable in the general population, beyond the diagnostic borders of the current nosological systems ICD and DSM (12). One of the first empirical investigations of this issue (13) observed in a sample of approximately 17,000 adults in Victorian England that about $8 \%$ of males and $12 \%$ of females reported at least one hallucination in their lifetime [see also Ref. (14)]. More recent systematic investigations by van Os and colleagues similarly document the existence of individual psychotic symptoms in the general population (12). In a comprehensive review of several population-based studies of the frequency of psychotic symptoms, it was found that over $8 \%$ of the population reports psychotic experiences and that these could be explained through the same etiological factors that also increase risk for non-affective psychoses (12).

In addition to the study of individual psychotic symptoms in the general population, Johns and van Os (15) proposed that there is a second approach to investigating population continua. That approach describes subclinical, attenuated trait-like expressions of the disorder ranging along a continuum in the form of schizotypal signs. This schizotypy approach is the focus of the present article ${ }^{1}$.

Together, the observation of individual psychotic symptoms and the description of subclinical schizotypal traits in the general population have led to the concept of the schizophrenia spectrum. This work is based on the notion of a non-binary distribution of schizophrenia (12), an assumption that is currently receiving widespread agreement in the literature (5).

Here, we examine the schizotypy approach in more detail and then focus on the overlap between schizotypy and schizophrenia. In doing so, we provide an overview of empirical work pointing to similarities between the two constructs not only at the level of phenomenology but also genetics, cognition, perception, motor control, and neurobiology. The argument proposed on the basis of these data is that schizotypal traits share not just superficial similarity with the signs and symptoms of schizophrenia but appear related to the clinical disorder at multiple levels of analysis.

\section{PHENOMENOLOGY AND MEASUREMENT OF SCHIZOTYPY}

The term schizotypy was coined by Rado (16). The large and methodologically heterogeneous literature on schizotypy can broadly be grouped into two approaches, viz. the so-called quasi-dimensional and fully dimensional approaches $(6,15,17)$.

According to Meehl $(18,19)$, schizotypy is the psychological and personality organization of most, but not all, individuals with schizotaxia. Schizotaxia is defined by Meehl as a neural defect due to a synaptic aberration termed hypokrisia, which is caused by a

\footnotetext{
${ }^{1}$ In this context, it is also important to point out that there are associations between the existence of individual psychotic symptoms and schizotypal traits $(44,218,219)$, which speak for the integration of these two literatures. Such observations are to be expected under the assumption that higher trait schizotypy scores along the continuum from normal personality to schizophrenia will be associated with increasing manifestations of psychosis.
}

single gene, the schizogene. According to Meehl, schizotaxia has a population base rate of about $10 \%$. Meehl's quasi-dimensional, psychiatrically oriented approach considers schizotypy as the subclinical expression of the symptoms of schizophrenia $(20,21)$. Evidence for this approach stems from taxometric studies (22), although there are also failures to provide evidence of a taxon (7).

The fully dimensional approach (23) is rooted in differential psychology and is based on the work of Eysenck and Claridge $(7,24-27)$. This approach treats schizotypy as a personality trait that is continually distributed in the general population. This trait shows individual differences and results, at its extreme high end, in a diagnosis of schizophrenia. Evidence for this approach stems from taxometric studies that consider positive skewness of sample distribution (7). The high prevalence of psychotic-like experiences in the general population is also in accordance with the fully dimensional approach $(28,29)$.

Theoretical issues aside, both approaches agree that there is variation in schizotypal features in the population, although specific details concerning the nature of the distribution (for example, the question of whether there is a taxon or not) have not been finally resolved $(7,15,22)$.

Schizotypy can be assessed in the general population (30, 31) using clinical interviews [such as the Structured Interview for Schizotypy (32)] or psychometric self-report questionnaires [ such as the Schizotypal Personality Questionnaire (SPQ (33)), the Oxford-Liverpool Inventory of Feelings and Experiences (O-LIFE (34)), the Rust Inventory of Schizotypal Cognitions (RISC (35)), the Community Assessment of Psychic Experiences (CAPE (36)), the Schizotypal Personality Scale (STA (37)), the Peters et al. Delusions Inventory (PDI (38)), the Eysenck Psychoticism (P) Scale (39), or the Chapman scales (40)]. Sample items from the SPQ are shown in Table 1.

The psychometric structure of schizotypy has been examined in numerous factor analyses of questionnaire data. Overall, there appears to be some agreement in the literature that the variance of schizotypy is well explained by a three-factor structure including the following dimensions (41). The "cognitive-perceptual" dimension (also referred to as positive schizotypy) includes perceptual alterations that bear some resemblance to the hallucinations reported in schizophrenia. It also includes unusual thoughts and views that resemble the delusions of schizophrenia. The "disorganized" dimension includes formal thought disorder and eccentric behavior. Finally, the "interpersonal" dimension (also referred to as negative schizotypy) is characterized by the loss of emotional, physical, and social functions such as pleasure, volition, interest in social contacts, and emotionality. Altogether the phenomenology of schizotypy thus possesses considerable similarity with the factor structure of schizophrenia (42).

The three-factor structure of schizotypy has been recovered independent of variables such as gender, culture, and religion (43). Individual differences in schizotypy can be measured with high reliability and possess high temporal stability $(33-35,44)$. It should also be noted that the scores of psychometric self-report questionnaires correlate highly with observer-ratings gained from clinical interviews $(33,45)$, further supporting the validity of these measures. 


\begin{tabular}{|c|c|}
\hline Item & SPQ dimension \\
\hline Do you sometimes feel that things you see on the TV or read in the newspaper have a special meaning for you? & Ideas of reference (Pos) \\
\hline I often hear a voice speaking my thoughts aloud & Unusual perceptual experiences (Pos) \\
\hline I feel I have to be on my guard even with friends & Suspiciousness (Pos) \\
\hline I sometimes jump quickly from one topic to another when speaking & Odd speech (Dis) \\
\hline I sometimes use words in unusual ways & Odd speech (Dis) \\
\hline My "non-verbal" communication (smiling and nodding during a conversation) is not very good & Constricted affect (Neg) \\
\hline I prefer to keep myself to myself & No close friends (Neg) \\
\hline
\end{tabular}

The items are taken from the Schizotypal Personality Questionnaire (SPQ). Pos: the positive dimension of schizotypy; Dis: the disorganization dimension of schizotypy; Neg: the negative dimension of schizotypy.

\section{GENETIC, COGNITIVE, AND NEUROBIOLOGICAL STUDIES OF SCHIZOTYPY: OVERLAP WITH SCHIZOPHRENIA?}

The description of schizotypy in the preceding section provides clear evidence of its phenomenological overlap with schizophrenia. This evidence is complemented by empirical studies further investigating such putative overlap on different levels of analysis, namely (1) genetic and non-genetic etiological influences, (2) cognition, perception, and motor control, (3) brain structure and function, and (4) psychopharmacology. In the following part of this article, we will provide an overview of that work. As will become clear from the following discussion, these studies provide strong support for similarities between schizotypy and schizophrenia across these multiple analysis domains.

Due to the large number of studies on schizotypy, the following review is not comprehensive. We do, however, provide a table summarizing the key details of all available functional magnetic resonance imaging (fMRI) studies of schizotypy (Table 2).

\section{GENETIC AND ENVIRONMENTAL RISK FACTORS}

Behavioral genetic studies estimate the heritability of schizophrenia to be approximately $66-83 \%$ (60) and that of schizotypy to be around 30-50\% (61-64), although lower estimates have also been reported for schizotypy (65). Evidence of genetic overlap between schizophrenia and schizotypy comes from family studies, which show that first-degree relatives of schizophrenia patients have increased levels of schizotypy $(66,67)$, particularly in the negative dimension (68). In addition to increased mean levels of schizotypy in the relatives compared to controls without a first-degree relative with schizophrenia, there are also reports of associations between the profile and severity of clinical symptoms in the patients and the dimensions of schizotypy in the relatives (69). For example, one study showed that the severity of positive symptoms in psychotic patients was associated with the level of positive schizotypy in the relatives, similar to the findings of another study on negative schizotypy (70). Overall, these studies provide evidence for genetic, or at least familial, correlations between schizotypy and schizophrenia.

More recent molecular genetic data complement these behavioral genetic studies. For example, a genome-wide association study (GWAS) showed considerable overlap between the genetic association profiles of schizophrenia and schizotypy (71). Put together, these molecular genetic studies point to considerable overlap of schizotypy with schizophrenia at the genetic level by implicating similar polymorphisms in both phenotypes.

In addition to genetics, environmental risk factors are also known to play an important role in the etiology of schizophrenia, including winter or spring birth (72), growing up in an urban area (73), being an ethnic minority (74), childhood trauma (75), and cannabis use (76). These factors also increase the risk for subclinical spectrum phenotypes, again supporting the notion of overlap in etiological factors between schizophrenia and its subclinical expression (15).

\section{COGNITION, PERCEPTION, AND MOTOR CONTROL}

A large body of work has documented cross-domain deficits in automatic and controlled cognition, perception, and motor control in schizophrenia. Meta-analyses suggest that the most pronounced deficits are in the domains of verbal learning and memory, working memory, attention and executive functions as well as psychomotor control (77).

Complementing the work on schizophrenia, there have been numerous investigations of cognition, perception, and motor control in relation to schizotypy. The overall finding that emerges from these investigations is that high levels of schizotypy are associated with subtle performance deficits, mostly compatible with the pattern of findings observed, albeit at greater severity, in schizophrenia. The literature on cognition has been qualitatively reviewed in a number of recent publications $(6,17,21)$. A comprehensive meta-analysis of the association between all aspects of cognition, perception, and motor control with schizotypy using different study designs is missing, although a recent study calculated effect sizes for measures of cognition in a selection of studies that included a psychometrically defined schizotypy group drawn from the population of college students (78). That analysis did not find a strong effect size for the comparison between schizotypy groups and controls, but is limited not only by the sample inclusion criterion but also the exclusion of neurocognitive measures such as prepulse inhibition and oculomotor tasks, measures known to be reliably associated with schizotypy (see below).

Here, the key findings of studies examining the association between schizotypy and cognition, perception, and motor control will be highlighted briefly. These studies have generally followed one of two designs, by either comparing groups of individuals with high scores on psychometric schizotypy questionnaires to those with medium or low scores on these questionnaires in an 


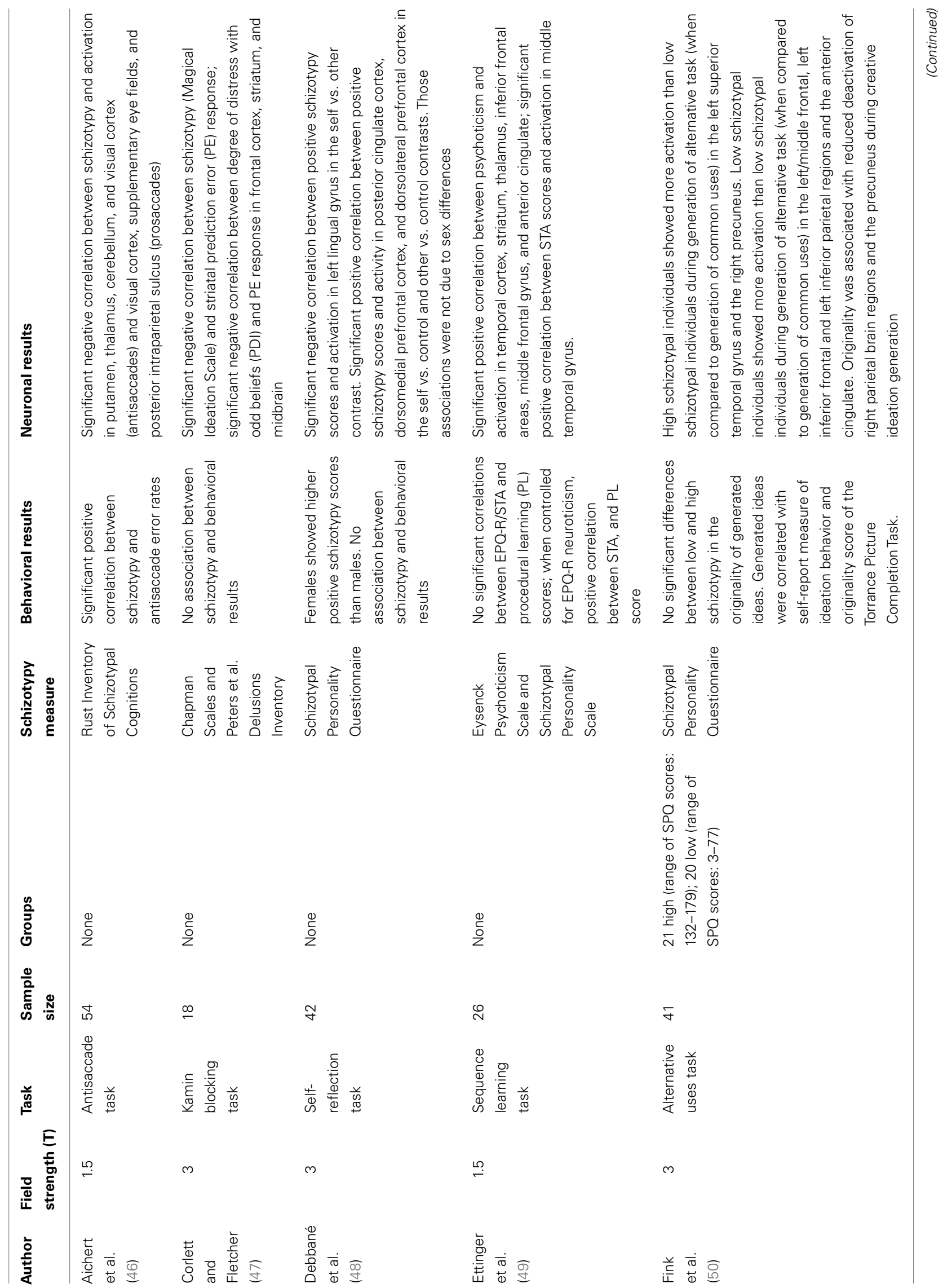




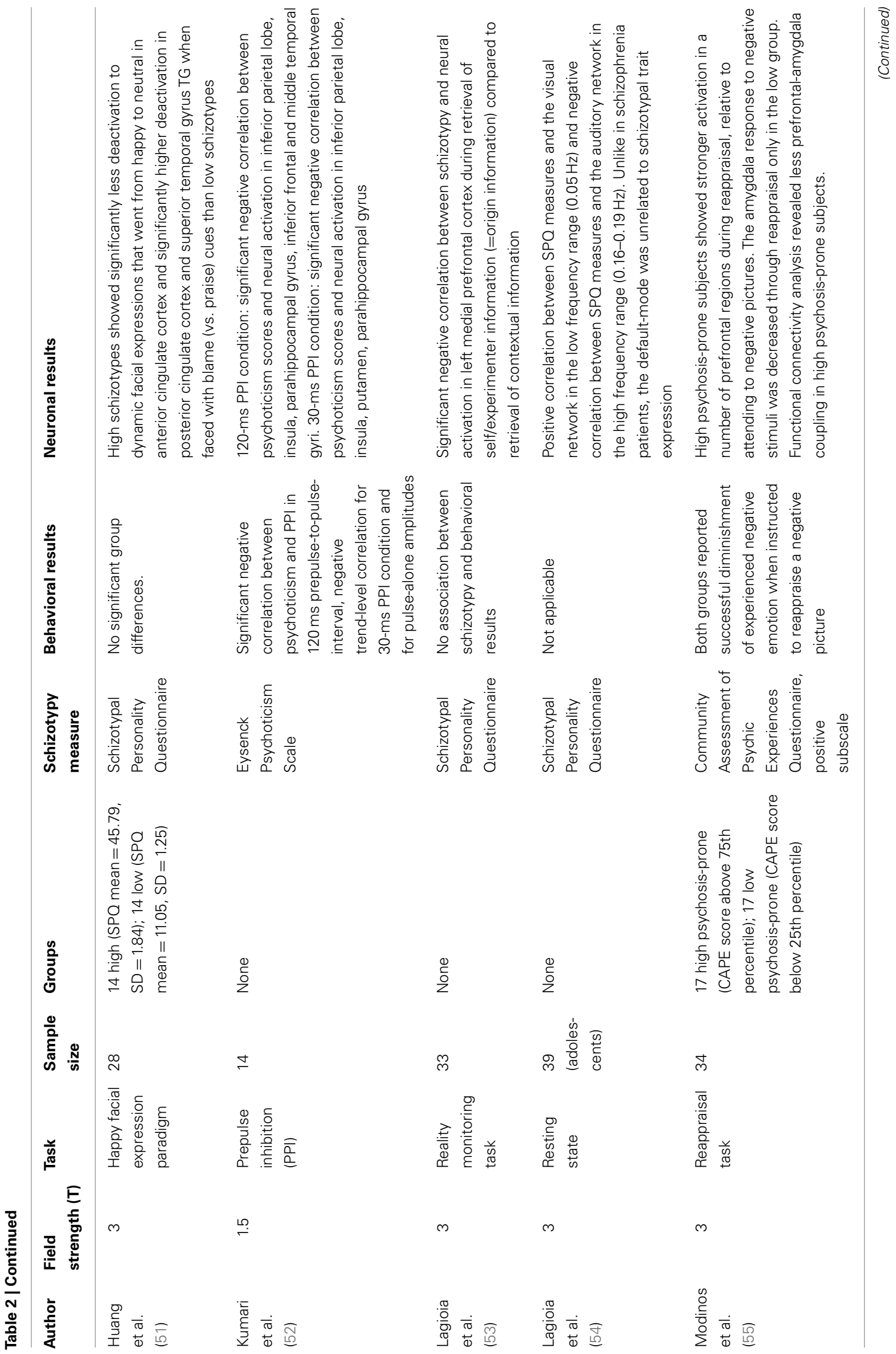




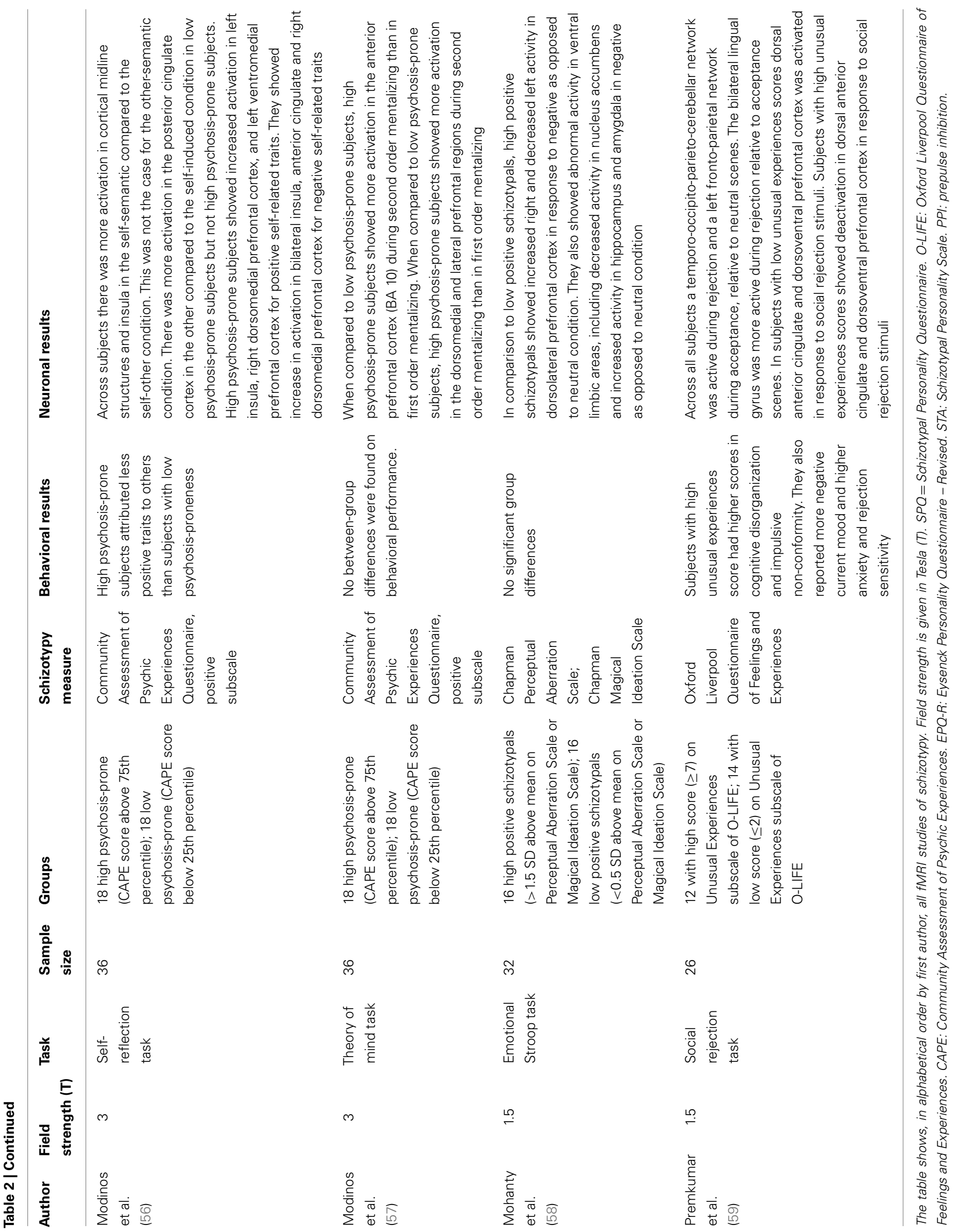


extreme groups approach or by investigating correlations between schizotypy questionnaire scores and task performance in samples not selected $a$ priori according to specific schizotypy cut-offs.

Regarding cognition, these studies have shown that higher levels of schizotypy are associated with impairments in working memory (79-84), in executive functions [Wisconsin Card Sorting Test, WCST: (79, 85-87); verbal fluency: (88)], in early sensorimotor filtering in the prepulse inhibition paradigm [PPI; (52, 89-91)], in visual backward masking (87), in the flexible adaptation of behavioral control following cognitive conflict (92), in the latent inhibition learning paradigm (93), in the recognition and naming of emotional facial expressions $(94,95)$, in attention [Continuous Performance Test, CPT; $(96,97)]$, in perspective taking regarding visual stimuli (98) as well as one's own body $(99,100)$, and in Theory of Mind (101). The deficits observed on these tasks are generally similar in kind to those observed in schizophrenia.

In addition, schizotypy is also associated with perceptual deficits, such as in the discrimination of auditory (102) and olfactory stimuli (103), and motor impairments. Motor impairments similar to those observed in schizophrenia were found by assessment of neurological soft signs (104,105), gait (106), and the precision of manual motor control (107). Moreover, the smooth pursuit and antisaccade eye movement deficits that are well described in schizophrenia $(108,109)$ are also observed in schizotypy [antisaccades: (110-112); smooth pursuit (112-115)]. These include a reduced ability to match eye velocity to target velocity in the smooth pursuit task and the failure to inhibit automatic saccades to a peripheral target in the antisaccade task.

The levels of impairment in different cognitive domains have also been related to the participants' specific schizotypy profile. For example, it was found that people with negative schizotypy $(88,116-118)$ as well as disorganized features $(87,88)$ are particularly impaired in frontally mediated executive functions, whereas cognition and behavior of people with positive schizotypy suggest impairments in temporo-limbic circuits (117). Gait abnormalities were also observed in positive but not negative schizotypy (106).

Of importance in this context is the observation that at least some of these neurocognitive deficits survive statistical correction for factors such as intelligence $(88,92)$ and neuroticism (92, 110), providing further support for the existence of genuine cognitive impairments in people with high levels of schizotypy, over and above these measures of general (cognitive or emotional) functioning.

In contrast to the deficits described above, there are only relatively few cognitive functions that are not found to be impaired in schizotypy. For example, relatively inconsistent findings are observed in the negative priming paradigm $(89,119)$ and the Stroop task (89, 120-126). Additionally, Raine (41) argues that the level of general intelligence is relatively unimpaired in schizotypy. Finally, there are reports of cognitive domains where higher levels of schizotypy are associated with better performance, for example, in measures of creativity (127-129).

\section{BRAIN STRUCTURE}

Since the early observation of enlarged ventricles (130) in schizophrenia, there have been numerous computed tomography (CT) and structural magnetic resonance imaging (MRI) studies of the brain in this disorder. A number of reviews of this literature are available $(131,132)$. Overall, these reviews have shown that patients with schizophrenia, when compared to healthy controls, show gray matter volume reductions in a number of brain areas. These volume reductions are most pronounced in temporal, parietal, and frontal cortical areas, hippocampus, amygdala, and cerebellum. Additionally, there is evidence of ventricular enlargement. Taken together, these results point to a non-localized pattern of structural changes, compatible with the hypothesis of schizophrenia as dysconnectivity syndrome (133-135).

Extending this line of research into schizotypy, structural MRI studies have investigated associations between the level of schizotypy and measures of gray and white matter volume in clinically unaffected individuals with the aim to search for schizophrenialike volumetric changes in high schizotypy. An early $0.15 \mathrm{~T}$ MRI study of 17 healthy subjects showed that higher overall levels of several schizotypy scales were associated with a lower area of the left prefrontal cortex as well as a lower area ratio of prefrontal cortex to temporal cortex (86), compatible with prefrontal volume reductions in schizophrenia. A more recent study, however, showed that healthy individuals with higher levels of positive schizotypy (measured using the CAPE) had larger whole-brain volumes as well as posterior cingulate and precuneus volumes (136). This positive association, which is not in agreement with the hypothesis of similar brain structural deficits in schizotypy and schizophrenia, possibly suggests that protective or compensatory mechanisms are operational in people with high levels of schizotypy but without the diagnosis of schizophrenia. Such a conclusion is in agreement with another structural MRI study, which reported a positive association of overall schizotypy levels (SPQ) and cortical thickness in the frontal lobe (137). However, the same study also observed a negative association between schizotypy and thalamic volume (137), compatible with reports of thalamic volume reductions in schizophrenia $(138,139)$. Finally, we recently observed that higher levels of positive schizotypy (35) were associated with volume reductions in frontal and temporal cortical areas, significantly overlapping with the pattern of volumetric reductions typically observed in schizophrenia (140).

These investigations of gray matter volumes in schizotypy have been most recently complemented by MRI studies of white matter. A diffusion tensor imaging (DTI) study (141) compared people with high MMPI-2 (Minnesota Multiphasic Personality Inventory) mean scores in the psychosis-like Sc (Schizophrenia), $\mathrm{Pa}$ (Paranoia), and Pd (Psychopathic Deviate) scales with controls with low scores. The group with high scores had higher fractional anisotropy (FA) in the left arcuate fasciculus, but lower FA in the right arcuate fasciculus in fronto-parieto-temporal tracts and in the corpus callosum. Another study (142) showed that higher cognitive-perceptual factor scores of the SPQ were associated with lower white matter integrity in fronto-temporal tracts, in the bilateral anterior thalamic radiation and the forceps minor.

In addition to these studies of psychometric schizotypy, there are a number of MRI studies of patients with a clinical diagnosis of schizotypal personality disorder $\left(\mathrm{SPD}^{2}\right)$, a clinical disorder

${ }^{2}$ It should be pointed out here that high levels of schizotypy on psychometric selfreport questionnaires may result in a diagnosis of SPD, but not necessarily so. For 
with a population prevalence of approximately 3.9\%. The findings from these studies have recently been reviewed in detail elsewhere $(143,144)$ and are only summarized briefly here. In short, volume reductions in SPD are seen in the temporal lobe, similar to findings from schizophrenia. However, it has also been found that SPD patients do not display the frontal lobe volume reductions observed in schizophrenia, possibly reflecting protective or compensatory processes. Detailed investigations of subcortical structures support this claim: both schizophrenia and SPD show volume reductions in the thalamic pulvinar, a structure that shows prominent connections with the temporal lobe, but not in the mediodorsal nucleus, which is primarily connected with the frontal lobe (145). A recent study yielded distributed gray matter volume reductions in frontal, parietal, and temporal areas in an important sample of antipsychotic-naïve men with SPD (143), suggesting that these deficits are not due to (long-term) antipsychotic treatment.

\section{BRAIN FUNCTION}

A still relatively small - but growing - body of work has used fMRI to investigate the functional neuronal correlates of schizotypy. The key features and findings from these studies are summarized in Table 2.

Amongst these studies, there is concrete evidence of similarity in neural activation patterns between schizophrenia and schizotypy. For example, the above mentioned PPI paradigm, a measure of early attentional processing, was found to be associated with reduced activation in the insula, putamen, thalamus inferior parietal cortex, hippocampal gyrus, and fusiform gyrus in persons with high levels of psychoticism (P) (52). These activation reductions resemble the data obtained from samples of patients with schizophrenia $(146,147)$.

Further evidence for brain functional similarity between schizotypy and schizophrenia was reported by Corlett and Fletcher (47). In an fMRI study of the Kamin blocking task, these authors observed an association of lower BOLD signal in the striatum during unexpected "prediction error" trials with higher schizotypy scores and an association between distress with unusual beliefs and variation in prediction error related signal in the right frontal cortex. The latter finding is directly compatible with data from earlier investigations of the prediction error effect in schizophrenia (148) and following administration of ketamine (149), a non-competitive NMDA receptor antagonist known to cause psychosis-like states (150).

Additionally, the already mentioned behavioral deficits in antisaccade performance in schizotypy were found to be associated with reduced activation levels in the striatum, thalamus, cerebellum, and occipital cortex (46). This pattern resembles fMRI studies of volitional saccades in schizophrenia patients [striatum:

example, Raine (33) reported that a diagnosis of SPD was made amongst $55 \%$ of people with SPQ scores in the top 10\% of the distribution (compared to $0 \%$ of people from the lowest $10 \%$ of the distribution). According to ICD-10, a personality disorder is characterized by an inflexible, rigid personality that leads to considerable psychological strain. Therefore, it is important to mention that although all patients with a SPD diagnosis are likely to have high levels of schizotypy on a psychometric questionnaire, not all high psychometric schizotypes meet the diagnostic criteria for SPD.
(151-153)] and their unaffected relatives [striatum: (154), occipital cortex: (155)], although reductions in frontal lobe activation levels were additionally described in schizophrenia (152) but not in schizotypy.

Finally, qualitative alterations in the neural processing patterns underlying a number of other paradigms have also been found in schizotypy, e.g., in an emotional Stroop task in students with high levels of positive schizotypy (58). A series of publications on a sample of students with high CAPE scores showed (i) increased activation in prefrontal areas in a second order Theory of Mind task despite unimpaired behavioral performance (55), (ii) reduced prefrontal control of emotional processing (57), and (iii) altered activation patterns during the processing of self-related stimuli (56). In another study, people with high levels of schizotypy were found to deactivate the dorsal anterior cingulate cortex (ACC) whilst viewing pictures of social rejection, similar to what has been found in depressed patients, whereas controls activated the same structure (59). Huang and colleagues (51) on the other hand found that people with high SPQ scores showed weaker deactivations in right ACC and stronger deactivations in left posterior cingulate cortex and right superior temporal gyrus (STG) when viewing happy faces. Debbané and colleagues (48) examined the neural correlates of self-reflective processes and positive psychometric schizotypy in adolescence using a trait evaluation task. A negative association was found between schizotypy and activation in left lingual gyrus while the participants were rating themselves compared to others. During the ratings of self vs. control and other vs. control, schizotypal traits were positively correlated with activity in posterior cingulate cortex and dorsolateral and dorsomedial prefrontal cortex. Using a reality monitoring task in adolescents an association was found between higher SPQ scores and reduced activation in BA10 during judgments of whether a word was generated by the participant or the experimenter (53). In a study on the association between high positive schizotypy and creativity, Fink and colleagues (50) found similarities in the brain activation between schizotypy and creativity (as measured by originality) during creative ideation. Both high scores on the O-LIFE unusual experiences scale and originality were associated with reduced deactivation in right parietal brain regions and the precuneus during creative idea generation. Finally, the implementation of a dopamine-sensitive procedural learning task in fMRI yielded positive associations between EPQ-R (39) psychoticism scores and BOLD signal in striatum, thalamus, insula, and frontal cortex as well as between STA scores (37) and BOLD signal in right temporal cortex (49).

The observation that stress is a possible risk factor for schizophrenia (156) has led to an fMRI study of the neuronal response to stress in participants with high schizotypy (157). Differences in striatal and limbic activation patterns were found in participants with negative schizotypy in comparison to controls. These findings complement an earlier positron emission tomography (PET) study by the same group, in which participants with negative schizotypy were found to show greater stress-induced striatal dopamine release (158).

Apart from these studies of cognitive or emotional activation paradigms, more recently the investigation of brain function at "rest," i.e., in the absence of an overt task, has become 
increasingly instructive. Patients with schizophrenia have been found to show alterations in the resting-state activation patterns (159). The only resting-state fMRI study of schizotypy reported positive correlations between SPQ scores and a visual network in the low frequency range as well as negative correlations between SPQ scores and an auditory network in young people aged 12-20 years (54).

Several fMRI studies of SPD are also available. A first study by Koenigsberg and colleagues (160) showed that patients with SPD displayed reduced activations in distributed fronto-parietal areas during the retention interval of a visuo-spatial working memory task. Dickey et al. (161) found that auditory discrimination, a measure also known to be impaired in schizophrenia, was associated in SPD with hyper responsive neuronal processing of deviant tones in temporal and parietal areas. In another study on auditory processing Dickey et al. showed (162) that the recognition of emotions (sad, happy, sarcastic, neutral) in the prosody of semantically neutral sentences was unimpaired in SPD; however, processing was associated with seemingly inefficient activation in the STG.

The relationship between schizotypy and brain function has also been investigated using electroencephalography (EEG). For example, it was found that high SPQ schizotypy is associated with a reduction in the P100 amplitude during a working memory task, suggesting the existence of early information processing deficits (81), similar to what had previously been found in schizophrenia (163). However, EEG studies have also pointed to later processing deficits. Klein and colleagues (164) observed a reduction in P300b amplitude in participants with higher overall schizotypy (SPQ), complementing P300 amplitude changes that had been reported in patients with schizophrenia and their relatives (165). In another study, stronger negativity in the N400 window was found to be associated with higher scores in the SPQ disorganized dimension (166). Koychev and colleagues (167) studied a working memory task and found that participants with high SPQ schizotypy had reduced network synchronization in the beta and gamma range in fronto-central and central-occipital regions, compatible with the observation of disturbed cortico-cortical connectivity in schizophrenia. Another study (99) found that the behavioral deficit in bodily perspective taking in schizotypy (168) was associated with an increased duration of activity of the right temporo-parietal junction. Additionally, there is a replicated association between reduced P50 suppression in EEG and increased schizotypy (169, 170), especially in the disorganized dimension (171), complementing findings of reduced P50 suppression in schizophrenia patients, their relatives, and SPD patients $(172,173)$.

Finally, a number of studies have employed functional nearinfrared spectroscopy (fNIRS) to probe relationships between brain function and schizotypy. These studies showed that (i) increased levels of divergent thinking in schizotypy is associate with stronger activity in right prefrontal cortex in healthy and schizophrenic subjects (129), (ii) higher overall schizotypy scores (SPQ) are associated with reduced activity in frontal cortex during the recognition of one's own face but with increased activity during the "Reading the Mind in the Eyes" task (174), and (iii) high schizotypal (SPQ) participants show stronger activity and a greater right $>$ left asymmetry during a letter fluency task $(175,176)$.

\section{PSYCHOPHARMACOLOGY}

Psychopharmacological methods have also been drawn upon to elucidate the neural basis of schizotypy as well as possible similarities with schizophrenia. A central observation in schizophrenia research is the finding of increased striatal dopamine release that is seen in the patients following the acute administration of amphetamine. Imaging studies have shown that patients with schizophrenia, both in the acute phase and in remission, show amphetamine-induced reductions in D2 and D3 dopamine receptor binding potential in the striatum $(177,178)$. Similar findings were obtained in patients with schizotypal personality disorder (179). Importantly, a relationship between striatal dopamine release after amphetamine and SPQ schizotypy was observed in a sample of non-clinical volunteers (180), providing support for a shared dopaminergic dysfunction in schizotypy and schizophrenia.

In a large, multi-center pharmacological study of SPQ schizotypy it was observed that the D2/D3 receptor antagonist amisulpride improved working memory and verbal fluency performance in persons with high levels of schizotypy but worsened it in medium schizotypal controls (181). Data from the same study showed that administration of $7 \mathrm{mg}$ risperidone led to deterioration in antisaccade task performance in medium schizotypy controls, whereas in high schizotypy a non-significant tendency toward improvement was observed (182), compatible with the improvements in antisaccade performance seen in schizophrenia with risperidone treatment $(183,184)$. Together, these data suggest that persons with high schizotypy benefit from antipsychotic compounds similar to patients with schizophrenia, or at least tolerate them, whereas controls do not. Finally, an EEG study of the semantic processing of words (185) showed that anterior components of the increased N400 potential in high schizotypy were reduced through a one-off administration of the antipsychotic olanzapine. This effect resembles findings from schizophrenia research $(186,187)$ and suggests a dampening of increased salience in high schizotypy, as in low schizotypal subjects there was no such effect of olanzapine.

Taken together, these pharmacological studies yield highly interesting evidence of similarity between schizotypy and schizophrenia with respect to the neurocognitive effects of psychotomimetic and antipsychotic compounds. However, evidence of differences between these groups has also been obtained. For example, the dopamine increasing substance levodopa leads to improvements in a mental rotation task in people with high positive schizotypy, whereas cognitive improvements in schizophrenia tend to be observed after treatment with dopamine antagonists. This pattern of effects was explained by drawing upon the nonlinear relationship between dopamine and performance along an inverted U-function (106).

\section{SUMMARY OF GENETICS, COGNITION, AND NEUROBIOLOGY}

Overall, the studies described in the previous sections provide support, across a number of methods and functional domains, of alterations in cognition, perception, motor control, and neurobiology in schizotypy. Importantly, many of these alterations are qualitatively similar to the impairments seen in schizophrenia, supporting the notion of similarity between schizotypy and schizophrenia. 
However, evidence of discontinuities is also reported in some cognitive tasks that do not consistently show impairments in schizotypy, such as the negative priming and Stroop tasks. Additionally, better performance in schizotypy has been observed on measures of creativity and some structural neuroimaging evidence exists of possibly protective or compensatory neural resources in schizotypy. Clearly, these putatively preserved (or enhanced) functions and structures need to be investigated further.

\section{SCHIZOTYPY: IMPORTANCE AND IMPLICATIONS FOR SCHIZOPHRENIA RESEARCH}

Taken together, the cited studies support the assumption of a continuum between schizophrenia and schizotypy at different levels of analysis (6). Accordingly, implications of our current understanding of schizotypy to schizophrenia research are based at least in part on the continuum hypothesis, as detailed in the following section.

First, the documentation of such a continuum provides important clues regarding the etiology of schizophrenia $(5,15)$. Continuously distributed (and reliably measured) phenotypes are suggested to be the result of multiple etiological factors. A multifactorial etiology of schizophrenia has frequently been postulated. Accordingly, current research focuses on multiple gene loci (188) as well as several environmental risk factors (156). Of further interest in this context is the assumption that highly schizotypal individuals may be undetected carriers of schizophrenia risk alleles, which may provide one answer to questions from evolutionary biology concerning the frequency of schizophrenia in the population $(128,189)$.

Second, in addition to providing clues regarding the etiology of schizophrenia, schizotypy is an important topic for investigations in its own right, not only because of the documented neurocognitive impairments but also because of its associations with a number of maladaptive behaviors and psychiatric symptoms. For example, high levels of schizotypy are associated with cigarette smoking (190-192) and consumption of drugs such as cannabis $(193,194)$, negative affect, post-traumatic stress disorder, anxiety disorders and depression (195-198), and lower social, educational, and professional levels of functioning $(197,199-207)$. Overall, it can be concluded that people with high levels of schizotypy display maladaptive behaviors and psychiatric symptoms and suffer a lower quality of life $(197,208)$. Therefore, a thorough characterization of the cognitive and neural correlates of schizotypy can lead to an improved understanding of these disturbances and development of appropriate therapies.

Third, there may also be merits of studying schizotypy as a model system of schizophrenia. A particularly promising application of such a model system is in relation to antipsychotic and pro-cognitive drug development, an area of clear need in the treatment of schizophrenia $(209,210)$. The methodological advantages of such a model system include the availability of cheap, reliable, and objective psychometric questionnaires (17, 190). Additionally, continuously distributed data possess high statistical power (211). Finally, studies of high schizotypes are not confounded by problems such as long-term pharmacological treatment or chronic hospitalization as is frequently encountered in schizophrenia research.
Fourth, some authors have argued that a conceptualization of schizophrenia as a spectrum disorder may lead to increase in psychoeducational and psychotherapeutic treatment success. For example, David (5) and Johns and van Os (15) argue that dimensional definitions of the symptoms of schizophrenia are less stigmatizing than categorical diagnoses, a factor that could contribute beneficially to treatment outcome.

Overall it has been argued $(190,212)$ that the continuum approach to etiological research possesses higher validity than the categorical approach. The latter, on the other hand, may yield better reliability and has of course unrivaled usefulness in clinical communication and decision making with regards to treatment strategies.

It is also important to point out differences between the schizotypy paradigm and other phenotypic and genotypic spectrum sample strategies within the wider context of schizophrenia research. For example, the popular and successful approach of studying the biological relatives of schizophrenia patients draws upon the principle of a genetic continuum (213). Two fundamental findings stemming from this large body of work are (i) the observation of schizophrenia-like signs and symptoms in the relatives and (ii) the identification of neural and cognitive endophenotypes. Endophenotypes, or intermediate phenotypes, are markers of the genetic vulnerability to the illness and may help to improve our understanding of the neuronal and behavioral effects of risk genes $(214,215)$.

A second, important schizophrenia-spectrum population that is currently under intense investigation is individuals at particularly high risk for developing the illness. Such individuals are identified from the general population on the basis of different trait and state factors and have been found to have a high frequency of conversion to schizophrenia (216), higher than that observed in psychometric schizotypy (217).

The schizotypy approach described here complements these genetic and high-risk approaches by adopting a psychometric criterion for the definition of this spectrum population.

\section{CONCLUSION}

In this article, we reviewed evidence of putative overlap between schizotypy and schizophrenia. We argued first that this overlap is apparent at the phenomenological level, with schizotypy traits resembling, in attenuated form, the signs and symptoms of schizophrenia. Importantly, we then provided evidence from genetic, cognitive, and neurobiological studies supporting the assumption that schizotypy shows significant similarity with schizophrenia also at these levels, suggesting that the observed similarity at the phenomenological level may not be trivial. Future work will be required to further characterize the boundary between high schizotypy and schizophrenia. Another area of research that deserves further attention concerns the identification of differences between schizotypy and schizophrenia. These may point to protective or even compensatory mechanisms that prevent high schizotypes from developing full-blown schizophrenia.

\section{ACKNOWLEDGMENTS}

This work was funded in part through the DFG Emmy Noether Programme (Et 31/2-1). 


\section{REFERENCES}

1. Gustavsson A, Svensson M, Jacobi F, Allgulander C, Alonso J, Beghi E, et al. Cost of disorders of the brain in Europe 2010. Eur Neuropsychopharmacol (2011) 21:718-79. doi:10.1016/j.euroneuro.2011.08.008

2. Mangalore R, Knapp M. Cost of schizophrenia in England. J Ment Health Policy Econ (2007) 10:23-41.

3. Konnopka A, Klingberg S, Wittorf A, Konig HH. The cost of schizophrenia in Germany: a systematic review of the literature. Psychiatr Prax (2009) 36:211-8. doi:10.1055/s-0028-1090234

4. Carpenter WT, Koenig JI. The evolution of drug development in schizophrenia: past issues and future opportunities. Neuropsychopharmacology (2008) 33:2061-79. doi:10.1038/sj.npp.1301639

5. David AS. Why we need more debate on whether psychotic symptoms lie on a continuum with normality. Psychol Med (2010) 40:1935-42. doi:10.1017/ S0033291710000188

6. Nelson MT, Seal ML, Pantelis C, Phillips LJ. Evidence of a dimensional relationship between schizotypy and schizophrenia: a systematic review. Neurosci Biobehav Rev (2013) 37:317-27. doi:10.1016/j.neubiorev.2013.01.004

7. Rawlings D, Williams B, Haslam N, Claridge G. Taxometric analysis supports a dimensional latent trait structure for schizotypy. Pers Individ Dif (2008) 44:1640-51. doi:10.1016/j.paid.2007.06.005

8. Murray RM, Lappin J, DiForti M. Schizophrenia: from developmental deviance to dopamine dysregulation. Eur Neuropsychopharmacol (2008) 18(Suppl 3):S129-34. doi:10.1016/j.euroneuro.2008.04.002

9. Poulton R, Caspi A, Moffitt TE, Cannon M, Murray R, Harrington H. Children's self-reported psychotic symptoms and adult schizophreniform disorder: a 15-year longitudinal study. Arch Gen Psychiatry (2000) 57:1053-8. doi:10.1001/archpsyc.57.11.1053

10. Hafner H. Onset and early course as determinants of the further course of schizophrenia. Acta Psychiatr Scand Suppl (2000) 102(Suppl 407):44-8. doi:10.1034/j.1600-0447.2000.00008.x

11. Strauss JS. Hallucinations and delusions as points on continua function. Rating scale evidence. Arch Gen Psychiatry (1969) 21:581-6. doi:10.1001/archpsyc. 1969.01740230069010

12. van Os J, Linscott RJ, Myin-Germeys I, Delespaul P, Krabbendam L. A systematic review and meta-analysis of the psychosis continuum: evidence for a psychosis proneness-persistence-impairment model of psychotic disorder. Psychol Med (2009) 39:179-95. doi:10.1017/S0033291708003814

13. Sidgwick H, Johnson A, Myers FWH, Podmore F, Sidgwick EM. Report on the census of hallucinations. Proc Soc Psychical Res (1894) 10:25.

14. Tien AY. Distribution of hallucinations in the population. Soc Psychiatry Psychiatr Epidemiol (1991) 26:287-92. doi:10.1007/BF00789221

15. Johns LC, van Os J. The continuity of psychotic experiences in the general population. Clin Psychol Rev (2001) 21:1125-41. doi:10.1016/S0272-7358(01) 00103-9

16. Rado S. Dynamics and classification of disordered behaviour. Am J Psychiatry (1953) 110:406-16.

17. Giakoumaki SG. Cognitive and prepulse inhibition deficits in psychometrically high schizotypal subjects in the general population: relevance to schizophrenia research. J Int Neuropsychol Soc (2012) 18:643-56.

18. Meehl PE. Schizotaxia, schizotypy, schizophrenia. Arch Gen Psychiatry (1962) 46:935-44. doi:10.1001/archpsyc.1989.01810100077015

19. Meehl PE. Toward an integrated theory of schizotaxia. J Pers Disord (1990) 4:1-99. doi:10.1521/pedi.1990.4.1.1

20. Meehl PE. Schizotaxia revisited. Arch Gen Psychiatry (1989) 46:935-44. doi:10.1001/archpsyc.1989.01810100077015

21. Lenzenweger MF. Schizotypy and Schizophrenia: The View from Experimental Psychopathology. New York: Guilford Press (2010).

22. Haslam N, Holland E, Kuppens P. Categories versus dimensions in personality and psychopathology: a quantitative review of taxometric research. Psychol Med (2012) 42:903-20. doi:10.1017/S0033291711001966

23. Claridge G. Schizotypy: Implications for Illness and Health. Oxford: OUP (1997).

24. Claridge G. The schizophrenias as nervous types. Br J Psychiatry (1972) 121:1-17. doi:10.1192/bjp.121.1.1

25. Claridge G. The schizophrenias as nervous types revisited. Br J Psychiatry (1987) 151:735-43. doi:10.1192/bjp.151.6.735
26. Eysenck HJ. The Biological Basis of Personality. Springfield: Charles C Thomas Publisher (1967).

27. Eysenck SB, Eysenck HJ. The measurement of psychoticism: a study of factor stability and reliability. Br J Soc Clin Psychol (1968) 7:286-94. doi:10.1111/j. 2044-8260.1968.tb00571.x

28. Barrett TR, Etheridge JB. Verbal hallucinations in normals, I: people who hear “voices". Appl Cogn Psychol (1992) 6:379-87. doi:10.1002/acp.2350060503

29. Lincoln TM. Relevant dimensions of delusions: continuing the continuum versus category debate. Schizophr Res (2007) 93:211-20. doi:10.1016/j.schres. 2007.02.013

30. Avramopoulos D, Stefanis NC, Hantoumi I, Smyrnis N, Evdokimidis I, Stefanis CN. Higher scores of self reported schizotypy in healthy young males carrying the COMT high activity allele. Mol Psychiatry (2002) 7:706-11. doi:10.1038/sj.mp.4001070

31. Lenzenweger MF, O'Driscoll GA. Smooth pursuit eye movement and schizotypy in the community. J Abnorm Psychol (2006) 115:779-86. doi:10.1037/ 0021-843X.115.4.779

32. Kendler KS, Lieberman JA, Walsh D. The Structured Interview for Schizotypy (SIS): a preliminary report. Schizophr Bull (1989) 15:559-71. doi:10.1093/ schbul/15.4.559

33. Raine A. The SPQ: a scale for the assessment of schizotypal personality based on DSM-III-R criteria. Schizophr Bull (1991) 17:555-64. doi:10.1093/schbul/ 17.4.555

34. Mason O, Claridge G. The Oxford-Liverpool Inventory of Feelings and Experiences (O-LIFE): further description and extended norms. Schizophr Res (2006) 82:203-11. doi:10.1016/j.schres.2005.12.845

35. Rust J. The rust inventory of schizotypal cognitions (RISC). Schizophr Bull (1988) 14:317-22. doi:10.1093/schbul/14.2.317

36. Stefanis NC, Hanssen M, Smirnis NK, Avramopoulos DA, Evdokimidis IK, Stefanis CN, et al. Evidence that three dimensions of psychosis have a distribution in the general population. Psychol Med (2002) 32:347-58. doi:10.1017/ S0033291701005141

37. Claridge G, Broks P. Schizotypy and hemisphere function I: theoretical considerations and the measurement of schizotypy. Pers Individ Diff(1984) 5:633-48. doi:10.1016/0191-8869(84)90111-9

38. Peters ER, Joseph SA, Garety PA. Measurement of delusional ideation in the normal population: introducing the PDI (Peters etal. Delusions Inventory). Schizophr Bull (1999) 25:553-76. doi:10.1093/oxfordjournals.schbul.a033401

39. Eysenck HJ, Eysenck SBG. Manual of the Eysenck personality Scales (EPS Adult). London: Hodder \& Stoughton (1991).

40. Chapman LJ, Kwapil TR. Scales for the measurement of schizotypy. In: Raine A, Lencz T, Mednick SA editors. Schizotypal Personality. Cambridge: Cambridge University Press (1995). p. 79-106.

41. Raine A. Schizotypal personality: neurodevelopmental and psychosocial trajectories. Annu Rev Clin Psychol (2006) 2:291-326. doi:10.1146/annurev.clinpsy. 2.022305.095318

42. Liddle PF. The symptoms of chronic schizophrenia. A re-examination of the positive-negative dichotomy. Br J Psychiatry (1987) 151:145-51. doi:10.1192/ bjp.151.2.145

43. Reynolds CA, Raine A, Mellingen K, Venables PH, Mednick SA. Threefactor model of schizotypal personality: invariance across culture, gender, religious affiliation, family adversity, and psychopathology. Schizophr Bull (2000) 26:603-18. doi:10.1093/oxfordjournals.schbul.a033481

44. Gross GM, Silvia PJ, Barrantes-Vidal N, Kwapil TR. Psychometric properties and validity of short forms of the Wisconsin Schizotypy Scales in two large samples. Schizophr Res (2012) 134:267-72. doi:10.1016/j.schres.2011.11.032

45. Konings M, Bak M, Hanssen M, van Os J, Krabbendam L. Validity and reliability of the CAPE: a self-report instrument for the measurement of psychotic experiences in the general population. Acta Psychiatr Scand (2006) 114:55-61. doi:10.1111/j.1600-0447.2005.00741.x

46. Aichert DS, Williams SC, Möller HJ, Kumari V, Ettinger U. Functional neural correlates of psychometric schizotypy: an fMRI study of antisaccades. Psychophysiology (2012) 49:345-56. doi:10.1111/j.1469-8986.2011.01306.x

47. Corlett PR, Fletcher PC. The neurobiology of schizotypy: fronto-striatal prediction error signal correlates with delusion-like beliefs in healthy people. $\mathrm{Neu}$ ropsychologia (2012) 50:3612-20. doi:10.1016/j.neuropsychologia.2012.09.045 
48. Debbané M, Vrticka P, Lazouret M, Badoud D, Sander D, Eliez S. Self-reflection and positive schizotypy in the adolescent brain. Schizophr Res (2014) 152:6572. doi:10.1016/j.schres.2013.06.027

49. Ettinger U, Corr PJ, Mofidi A, Williams SC, Kumari V. Dopaminergic basis of the psychosis-prone personality investigated with functional magnetic resonance imaging of procedural learning. Front Hum Neurosci (2013) 7:130. doi:10.3389/fnhum.2013.00130

50. Fink A, Weber B, Koschutnig K, Benedek M, Reishofer G, Ebner F, et al. Creativity and schizotypy from the neuroscience perspective. Cogn Affect Behav Neurosci (2013). doi:10.3758/s13415-013-0210-6

51. Huang J, Wang Y, Jin Z, Di X, Yang T, Gur RC, et al. Happy facial expression processing with different social interaction cues: an fMRI study of individuals with schizotypal personality traits. Prog Neuropsychopharmacol Biol Psychiatry (2013) 44:108-17. doi:10.1016/j.pnpbp.2013.02.004

52. Kumari V, Antonova E, Geyer MA. Prepulse inhibition and "psychosisproneness" in healthy individuals: an fMRI study. Eur Psychiatry (2008) 23:274-80. doi:10.1016/j.eurpsy.2007.11.006

53. Lagioia A, Eliez S, Schneider M, Simons JS, Van der Linden M, Debbané M. Neural correlates of reality monitoring during adolescence. Neuroimage (2011) 55:1393-400. doi:10.1016/j.neuroimage.2010.12.058

54. Lagioia A, Van DeVille D, Debbané M, Lazeyras F, Eliez S. Adolescent resting state networks and their associations with schizotypal trait expression. Front Syst Neurosci (2010) 4:35. doi:10.3389/fnsys.2010.00035

55. Modinos G, Renken R, Shamay-Tsoory SG, Ormel J, Aleman A. Neurobiological correlates of theory of mind in psychosis proneness. Neuropsychologia (2010) 48:3715-24. doi:10.1016/j.neuropsychologia.2010.09.030

56. Modinos G, Renken R, Ormel J, Aleman A. Self-reflection and the psychosisprone brain: an fMRI study. Neuropsychology (2011) 25:295-305. doi:10.1037/ a0021747

57. Modinos G, Ormel J, Aleman A. Altered activation and functional connectivity of neural systems supporting cognitive control of emotion in psychosis proneness. Schizophr Res (2010) 118:88-97. doi:10.1016/j.schres.2010.01.030

58. Mohanty A, Herrington JD, Koven NS, Fisher JE, Wenzel EA, Webb AG, et al. Neural mechanisms of affective interference in schizotypy. J Abnorm Psychol (2005) 114:16-27. doi:10.1037/0021-843X.114.1.16

59. Premkumar P, Ettinger U, Inchley-Mort S, Sumich A, Williams SC, Kuipers E, et al. Neural processing of social rejection: the role of schizotypal personality traits. Hum Brain Mapp (2012) 33:695-706. doi:10.1002/hbm.21243

60. Cardno AG, Marshall EJ, Coid B, MacDonald AM, Ribchester TR, Davies NJ, et al. Heritability estimates for psychotic disorders: the Maudsley twin psychosis series. Arch Gen Psychiatry (1999) 56:162-8. doi:10.1001/archpsyc. 56.2.162

61. Claridge G, Hewitt J. A biometrical study of schizotypy in a normal population. Pers Individ Diff(1987) 8:303-12. doi:10.1016/0191-8869(87)90030-4

62. Linney YM, Murray RM, Peters ER, MacDonald AM, Rijsdijk F, Sham PC. A quantitative genetic analysis of schizotypal personality traits. Psychol Med (2003) 33:803-16. doi:10.1017/S0033291703007906

63. Macare C, Bates TC, Heath AC, Martin NG, Ettinger U. Substantial genetic overlap between schizotypy and neuroticism: a twin study. Behav Genet (2012) 42:732-42. doi:10.1007/s10519-012-9558-6

64. Kendler KS, Hewitt J. The structure of self-report schizotypy in twins. J Pers Disord (1992) 6:1-17. doi:10.1521/pedi.1992.6.1.1

65. MacDonald AW, Pogue-Geile MF, Debski TT, Manuck S. Genetic and environmental influences on schizotypy: a community-based twin study. Schizophr Bull (2001) 27:47-58. doi:10.1093/oxfordjournals.schbul.a006859

66. Calkins ME, Curtis CE, Grove WM, Iacono WG. Multiple dimensions of schizotypy in first degree biological relatives of schizophrenia patients. Schizophr Bull (2004) 30:317-25. doi:10.1093/oxfordjournals.schbul.a007081

67. Yaralian PS, Raine A, Lencz T, Hooley JM, Bihrle SE, Mills S, et al. Elevated levels of cognitive-perceptual deficits in individuals with a family history of schizophrenia spectrum disorders. Schizophr Res (2000) 46:57-63. doi:10.1016/S0920-9964(99)00239-X

68. Tarbox SI, Pogue-Geile MF. A multivariate perspective on schizotypy and familial association with schizophrenia: a review. Clin Psychol Rev (2011) 31:1169-82. doi:10.1016/j.cpr.2011.07.002

69. Mata I, Gilvarry CM, Jones PB, Lewis SW, Murray RM, Sham PC. Schizotypal personality traits in nonpsychotic relatives are associated with positive symptoms in psychotic probands. Schizophr Bull (2003) 29:273-83. doi:10. 1093/oxfordjournals.schbul.a007004

70. Fanous A, Gardner C, Walsh D, Kendler KS. Relationship between positive and negative symptoms of schizophrenia and schizotypal symptoms in nonpsychotic relatives. Arch Gen Psychiatry (2001) 58:669-73. doi:10.1001/archpsyc. 58.7.669

71. Fanous AH, Neale MC, Gardner CO, Webb BT, Straub RE, O’Neill FA, et al. Significant correlation in linkage signals from genome-wide scans of schizophrenia and schizotypy. Mol Psychiatry (2007) 12:958-65. doi:10.1038/sj.mp. 4001996

72. Bolinskey PK, Iati CA, Hunter HK, Novi JH. Season of birth, mixedhandedness, and psychometric schizotypy: preliminary results from a prospective study. Psychiatry Res (2013) 208:210-4. doi:10.1016/j.psychres.2012.12.023

73. Krabbendam L, van Os J. Schizophrenia and urbanicity: a major environmental influence - conditional on genetic risk. Schizophr Bull (2005) 31:795-9. doi:10.1093/schbul/sbi060

74. Cantor-Graae E, Selten JP. Schizophrenia and migration: a meta-analysis and review. Am J Psychiatry (2005) 162:12-24. doi:10.1176/appi.ajp.162.1.12

75. Read J, van Os J, Morrison AP, Ross CA. Childhood trauma, psychosis and schizophrenia: a literature review with theoretical and clinical implications. Acta Psychiatr Scand (2005) 112:330-50. doi:10.1111/j.1600-0447.2005.00634.x

76. Henquet C, Murray R, Linszen D, van Os J. The environment and schizophrenia: the role of cannabis use. Schizophr Bull (2005) 31:608-12. doi:10.1093/ schbul/sbi027

77. Keefe RS, Harvey PD. Cognitive impairment in schizophrenia. Handb Exp Pharmacol (2012) 213:11-37. doi:10.1007/978-3-642-25758-2_2

78. Chun CA, Minor KS, Cohen AS. Neurocognition in psychometrically defined college schizotypy samples: we are not measuring the "right stuff". J Int Neuropsychol Soc (2013) 19:324-37. doi:10.1017/S135561771200152X

79. Park S, Holzman PS, Lenzenweger MF. Individual differences in spatial working memory in relation to schizotypy. J Abnorm Psychol (1995) 104:355-63. doi:10.1037/0021-843X.104.2.355

80. Park S, McTigue K. Working memory and the syndromes of schizotypal personality. Schizophr Res (1997) 26:213-20. doi:10.1016/S0920-9964(97)00051-0

81. Koychev I, El-Deredy W, Haenschel C, Deakin JF. Visual information processing deficits as biomarkers of vulnerability to schizophrenia: an eventrelated potential study in schizotypy. Neuropsychologia (2010) 48:2205-14. doi:10.1016/j.neuropsychologia.2010.04.014

82. Kerns JG, Becker TM. Communication disturbances, working memory, and emotion in people with elevated disorganized schizotypy. Schizophr Res (2008) 100:172-80. doi:10.1016/j.schres.2007.11.005

83. Matheson S, Langdon R. Schizotypal traits impact upon executive working memory and aspects of IQ. Psychiatry Res (2008) 159:207-14. doi:10.1016/j. psychres.2007.04.006

84. Tallent KA, Gooding DC. Working memory and Wisconsin Card Sorting Test performance in schizotypic individuals: a replication and extension. Psychiatry Res (1999) 89:161-70. doi:10.1016/S0165-1781(99)00101-8

85. Gooding DC, Kwapil TR, Tallent KA. Wisconsin Card Sorting Test deficits in schizotypic individuals. Schizophr Res (1999) 40:201-9. doi:10.1016/S09209964(99)00124-3

86. Raine A, Sheard C, Reynolds GP, Lencz T. Pre-frontal structural and functional deficits associated with individual differences in schizotypal personality. Schizophr Res (1992) 7:237-47. doi:10.1016/0920-9964(92)90018-Z

87. Cappe C, Herzog MH, Herzig DA, Brand A, Mohr C. Cognitive disorganisation in schizotypy is associated with deterioration in visual backward masking. Psychiatry Res (2012) 200:652-9. doi:10.1016/j.psychres.2012.07.001

88. Cochrane M, Petch I, Pickering AD. Aspects of cognitive functioning in schizotypy and schizophrenia: evidence for a continuum model. Psychiatry Res (2012) 196:230-4. doi:10.1016/j.psychres.2012.02.010

89. Swerdlow NR, Filion D, Geyer MA, Braff DL. "Normal” personality correlates of sensorimotor, cognitive, and visuospatial gating. Biol Psychiatry (1995) 37:286-99. doi:10.1016/0006-3223(94)00138-S

90. Kumari V, Toone B, Gray JA. Habituation and prepulse inhibition of the acoustic startle reflex: effects of smoking status and psychosis-proneness. Pers Individ Diff (1997) 23:183-91. doi:10.1016/S0191-8869(97)00045-7

91. Takahashi H, Iwase M, Canuet L, Yasuda Y, Ohi K, Fukumoto M, et al. Relationship between prepulse inhibition of acoustic startle response and 
schizotypy in healthy Japanese subjects. Psychophysiology (2010) 47:831-7. doi:10.1111/j.1469-8986.2010.01000.x

92. Völter C, Strobach T, Aichert DS, Wöstmann N, Costa A, Möller HJ, et al. Schizotypy and behavioural adjustment and the role of neuroticism. PLoS One (2012) 7:e30078. doi:10.1371/journal.pone.0030078

93. Kumari V, Ettinger U. Cognition, neuroscience, and applications to schizophrenia. In: Lubow RE editor. Latent Inhibition. Cambridge: Cambridge University Press (2010). p. 419-47.

94. Brown LA, Cohen AS. Facial emotion recognition in schizotypy: the role of accuracy and social cognitive bias. J Int Neuropsychol Soc (2010) 16:474-83. doi:10.1017/S135561771000007X

95. Germine LT, Hooker CI. Face emotion recognition is related to individual differences in psychosis-proneness. Psychol Med (2011) 41:937-47. doi:10.1017/ S0033291710001571

96. Bedwell JS, Kamath V, Baksh E. Comparison of three computer-administered cognitive tasks as putative endophenotypes of schizophrenia. Schizophr Res (2006) 88:36-46. doi:10.1016/j.schres.2006.08.002

97. Bergida H, Lenzenweger MF. Schizotypy and sustained attention: confirming evidence from an adult community sample. J Abnorm Psychol (2006) 115:545-51. doi:10.1037/0021-843X.115.3.545

98. Langdon R, Coltheart M. Visual perspective-taking and schizotypy: evidence for a simulation-based account of mentalizing in normal adults. Cognition (2001) 82:1-26. doi:10.1016/S0010-0277(01)00139-1

99. Arzy S, Mohr C, Michel CM, Blanke O. Duration and not strength of activation in temporo-parietal cortex positively correlates with schizotypy. Neuroimage (2007) 35:326-33. doi:10.1016/j.neuroimage.2006.11.027

100. Mohr C, Landis T, Brugger P. Lateralized semantic priming: modulation by levodopa, semantic distance, and participants' magical beliefs. Neuropsychiatr Dis Treat (2006) 2:71-84.

101. Morrison SC, Brown LA, Cohen AS. A multidimensional assessment of social cognition in psychometrically defined schizotypy. Psychiatry Res (2013) 210:1014-9. doi:10.1016/j.psychres.2013.08.020

102. Bates TC. The panmodal sensory imprecision hypothesis of schizophrenia: reduced auditory precision in schizotypy. Pers Individ Diff (2005) 38:437-49. doi:10.1016/j.paid.2004.04.021

103. Park S, Schoppe S. Olfactory identification deficit in relation to schizotypy. Schizophr Res (1997) 26:191-7. doi:10.1016/S0920-9964(97)00045-5

104. Obiols JE, Serrano F, Caparrós B, Subirá S, Barrantes N. Neurological soft signs in adolescents with poor performance on the continuous performance test: markers of liability for schizophrenia spectrum disorders? Psychiatry Res (1999) 86:217-28. doi:10.1016/S0165-1781(99)00039-6

105. Barkus E, Stirling J, Hopkins R, Lewis S. The presence of neurological soft signs along the psychosis proneness continuum. Schizophr Bull (2006) 32:573-7. doi:10.1093/schbul/sbj037

106. Mohr C, Landis T, Sandor PS, Fathi M, Brugger P. Nonstereotyped responding in positive schizotypy after a single dose of levodopa. Neuropsychopharmacology (2004) 29:1741-51. doi:10.1038/s..npp.1300500

107. Lenzenweger MF, Maher BA. Psychometric schizotypy and motor performance. J Abnorm Psychol (2002) 111:546-55. doi:10.1037/0021-843X.111.4.546

108. O'Driscoll GA, Callahan BL. Smooth pursuit in schizophrenia: a meta-analytic review of research since 1993. Brain Cogn (2008) 68:359-70. doi:10.1016/j. bandc.2008.08.023

109. Gooding DC, Basso MA. The tell-tale tasks: a review of saccadic research in psychiatric patient populations. Brain Cogn (2008) 68:371-90. doi:10.1016/j. bandc.2008.08.024

110. Ettinger U, Kumari V, Crawford TJ, Flak V, Sharma T, Davis RE, et al. Saccadic eye movements, schizotypy, and the role of neuroticism. Biol Psychol (2005) 68:61-78. doi:10.1016/j.biopsycho.2004.03.014

111. Gooding DC. Antisaccade task performance in questionnaire-identified schizotypes. Schizophr Res (1999) 35:157-66. doi:10.1016/S0920-9964(98)00120-0

112. O'Driscoll GA, Lenzenweger MF, Holzman PS. Antisaccades and smooth pursuit eye tracking and schizotypy. Arch Gen Psychiatry (1998) 55:837-43. doi:10.1001/archpsyc.55.9.837

113. Kendler KS, Ochs AL, Gorman AM, Hewitt JK, Ross DE, Mirsky AF. The structure of schizotypy: a pilot multitrait twin study. Psychiatry Res (1991) 36:19-36. doi:10.1016/0165-1781(91)90114-5
114. Gooding DC, Miller MD, Kwapil TR. Smooth pursuit eye tracking and visual fixation in psychosis-prone individuals. Psychiatry Res (2000) 93:41-54. doi:10.1016/S0165-1781(00)00113-X

115. Holahan ALV, O'Driscoll GA. Antisaccade and smooth pursuit performance in positive- and negative-symptom schizotypy. Schizophr Res (2005) 76:43-54. doi:10.1016/j.schres.2004.10.005

116. Barrantes-Vidal N, Fañanás L, Rosa A, Caparrós B, Dolors RibaM, Obiols JE. Neurocognitive, behavioural and neurodevelopmental correlates of schizotypy clusters in adolescents from the general population. Schizophr Res (2003) 61:293-302. doi:10.1016/S0920-9964(02)00321-3

117. Dinn WM, Harris CL, Aycicegi A, Greene P, Andover MS. Positive and negative schizotypy in a student sample: neurocognitive and clinical correlates. Schizophr Res (2002) 56:171-85. doi:10.1016/S0920-9964(01)00230-4

118. Suhr JA, Spitznagel MB. Factor versus cluster models of schizotypal traits. II: relation to neuropsychological impairment. Schizophr Res (2001) 52:241-50. doi:10.1016/S0920-9964(00)00185-7

119. Moritz S, Andresen B. Reduced negative priming in schizotypy: failure to replicate. Br J Clin Psychol (2004) 43:211-5. doi:10.1348/014466504323088060

120. Cimino M, Haywood M. Inhibition and facilitation in schizotypy. J Clin Exp Neuropsychol (2008) 30:187-98. doi:10.1080/13803390701336866

121. Martin EA, Kerns JG. Social anhedonia associated with poor evaluative processing but not with poor cognitive control. Psychiatry Res (2010) 178:419-24. doi:10.1016/j.psychres.2009.08.018

122. Kaplan O, Lubow RE. Ignoring irrelevant stimuli in latent inhibition and Stroop paradigms: the effects of schizotypy and gender. Psychiatry Res (2011) 186:40-5. doi:10.1016/j.psychres.2010.07.025

123. Wan L, Friedman BH, Boutros NN, Crawford HJ. P50 sensory gating and attentional performance. Int J Psychophysiol (2008) 67:91-100. doi:10.1016/j. ijpsycho.2007.10.008

124. Szöke A, Méary A, Ferchiou A, Trandafir A, Leboyer M, Schürhoff F. Correlations between cognitive performances and psychotic or schizotypal dimensions. Eur Psychiatry (2009) 24:244-50. doi:10.1016/j.eurpsy.2008.10.007

125. Suhr JA. Executive functioning deficits in hypothetically psychosis-prone college students. Schizophr Res (1997) 27:29-35. doi:10.1016/S0920-9964(97) 00072-8

126. Orem DM, Bedwell JS. A preliminary investigation on the relationship between color-word Stroop task performance and delusion-proneness in nonpsychiatric adults. Psychiatry Res (2010) 175:27-32. doi:10.1016/j.psychres. 2008.09.001

127. Weinstein S, Graves RE. Are creativity and schizotypy products of a right hemisphere bias? Brain Cogn (2002) 49:138-51. doi:10.1006/brcg.2001.1493

128. Nettle D, Clegg H. Schizotypy, creativity and mating success in humans. Proc Biol Sci (2006) 273:611-5. doi:10.1098/rspb.2005.3349

129. Folley BS, Park S. Verbal creativity and schizotypal personality in relation to prefrontal hemispheric laterality: a behavioral and near-infrared optical imaging study. Schizophr Res (2005) 80:271-82. doi:10.1016/j.schres.2005.06.016

130. Johnstone EC, Crow TJ, Frith CD, Husband J, Kreel L. Cerebral ventricular size and cognitive impairment in chronic schizophrenia. Lancet (1976) 2:924-6. doi:10.1016/S0140-6736(76)90890-4

131. Shenton ME, Whitford TJ, Kubicki M. Structural neuroimaging in schizophrenia: from methods to insights to treatments. Dialogues Clin Neurosci (2010) 12:317-32.

132. Shepherd AM, Laurens KR, Matheson SL, Carr VJ, Green MJ. Systematic metareview and quality assessment of the structural brain alterations in schizophrenia. Neurosci Biobehav Rev (2012) 36:1342-56. doi:10.1016/j.neubiorev.2011. 12.015

133. Andreasen NC, Nopoulos P, O’Leary DS, Miller DD, Wassink T, Flaum M. Defining the phenotype of schizophrenia: cognitive dysmetria and its neural mechanisms. Biol Psychiatry (1999) 46:908-20. doi:10.1016/S0006-3223(99) 00152-3

134. Stephan KE, Friston KJ, Frith CD. Dysconnection in schizophrenia: from abnormal synaptic plasticity to failures of self-monitoring. Schizophr Bull (2009) 35:509-27. doi: $10.1093 /$ schbul/sbn176

135. Uhlhaas PJ. Dysconnectivity, large-scale networks and neuronal dynamics in schizophrenia. Curr Opin Neurobiol (2013) 23:283-90. doi:10.1016/j.conb. 2012.11.004 
136. Modinos G, Mechelli A, Ormel J, Groenewold NA, Aleman A, McGuire PK. Schizotypy and brain structure: a voxel-based morphometry study. Psychol Med (2010) 40:1423-31. doi:10.1017/S0033291709991875

137. Kuhn S, Schubert F, Gallinat J. Higher prefrontal cortical thickness in high schizotypal personality trait. J Psychiatr Res (2012) 46:960-5. doi:10.1016/j. jpsychires.2012.04.007

138. Ettinger U, Chitnis XA, Kumari V, Fannon DG, Sumich AL, O’Ceallaigh S, et al. Magnetic resonance imaging of the thalamus in first-episode psychosis. Am J Psychiatry (2001) 158:116-8. doi:10.1176/appi.ajp.158.1.116

139. Ettinger U, Picchioni M, Landau S, Matsumoto K, van Haren NE, Marshall $\mathrm{N}$, et al. Magnetic resonance imaging of the thalamus and adhesio interthalamica in twins with schizophrenia. Arch Gen Psychiatry (2007) 64:401-9. doi:10.1001/archpsyc.64.4.401

140. Ettinger U, Williams SC, Meisenzahl EM, Möller HJ, Kumari V, Koutsouleris N. Association between brain structure and psychometric schizotypy in healthy individuals. World J Biol Psychiatry (2012) 13:544-9. doi:10.3109/15622975. 2011.559269

141. Volpe U, Federspiel A, Mucci A, Dierks T, Frank A, Wahlund LO, et al. Cerebral connectivity and psychotic personality traits. A diffusion tensor imaging study. Eur Arch Psychiatry Clin Neurosci (2008) 258:292-9. doi:10.1007/s00406-0070796- 1

142. Nelson MT, Seal ML, Phillips LJ, Merritt AH, Wilson R, Pantelis C. An investigation of the relationship between cortical connectivity and schizotypy in the general population. J Nerv Ment Dis (2011) 199:348-53. doi:10.1097/NMD. 0b013e318217514b

143. Asami T, Whitford TJ, Bouix S, Dickey CC, Niznikiewicz M, Shenton ME, et al. Globally and locally reduced MRI gray matter volumes in neurolepticnaive men with schizotypal personality disorder: association with negative symptoms. JAMA Psychiatry (2013) 70:361-72. doi:10.1001/jamapsychiatry. 2013.665

144. Hazlett EA, Goldstein KE, Kolaitis JC. A review of structural MRI and diffusion tensor imaging in schizotypal personality disorder. Curr Psychiatry Rep (2012) 14:70-8. doi:10.1007/s11920-011-0241-z

145. Byne W, Buchsbaum MS, Kemether E, Hazlett EA, Shinwari A, Mitropoulou $\mathrm{V}$, et al. Magnetic resonance imaging of the thalamic mediodorsal nucleus and pulvinar in schizophrenia and schizotypal personality disorder. Arch Gen Psychiatry (2001) 58:133-40. doi:10.1001/archpsyc.58.2.133

146. Kumari V, Gray JA, Geyer MA, ffytche D, Soni W, Mitterschiffthaler MT, et al. Neural correlates of tactile prepulse inhibition: a functional MRI study in normal and schizophrenic subjects. Psychiatry Res (2003) 122:99-113. doi:10.1016/S0925-4927(02)00123-3

147. Kumari V, Antonova E, Geyer MA, Ffytche D, Williams SC, Sharma T. A fMRI investigation of startle gating deficits in schizophrenia patients treated with typical or atypical antipsychotics. Int J Neuropsychopharmacol (2007) 10:463-77. doi:10.1017/S1461145706007139

148. Corlett PR, Murray GK, Honey GD, Aitken MR, Shanks DR, Robbins TW, et al. Disrupted prediction-error signal in psychosis: evidence for an associative account of delusions. Brain (2007) 130:2387-400. doi:10.1093/brain/awm173

149. Corlett PR, Honey GD, Aitken MR, Dickinson A, Shanks DR, Absalom AR, et al. Frontal responses during learning predict vulnerability to the psychotogenic effects of ketamine: linking cognition, brain activity, and psychosis. Arch Gen Psychiatry (2006) 63:611-21. doi:10.1001/archpsyc.63.6.611

150. Krystal JH, Karper LP, Seibyl JP, Freeman GK, Delaney R, Bremner JD, et al. Subanesthetic effects of the noncompetitive NMDA antagonist, ketamine, in humans. Psychotomimetic, perceptual, cognitive, and neuroendocrine responses. Arch Gen Psychiatry (1994) 51:199-214. doi:10.1001/archpsyc.1994. 03950030035004

151. Crawford TJ, Puri BK, Nijran KS, Jones B, Kennard C, Lewis SW. Abnormal saccadic distractibility in patients with schizophrenia: a 99mTc-HMPAO SPET study. Psychol Med (1996) 26:265-77. doi:10.1017/S0033291700034668

152. McDowell JE, Brown GG, Paulus M, Martinez A, Stewart SE, Dubowitz DJ, et al. Neural correlates of refixation saccades and antisaccades in normal and schizophrenia subjects. Biol Psychiatry (2002) 51:216-23. doi:10.1016/S00063223(01)01204-5

153. Raemaekers M, Jansma JM, Cahn W, Van der Geest JN, van der Linden JA, Kahn RS, et al. Neuronal substrate of the saccadic inhibition deficit in schizophrenia investigated with 3-dimensional event-related functional magnetic resonance imaging. Arch Gen Psychiatry (2002) 59:313-20. doi:10.1001/archpsyc.59.4.313
154. Raemaekers M, Ramsey NF, Vink M, van den Heuvel MP, Kahn RS. Brain activation during antisaccades in unaffected relatives of schizophrenic patients. Biol Psychiatry (2006) 59:530-5. doi:10.1016/j.biopsych.2005.07.030

155. Camchong J, Dyckman KA, Austin BP, Clementz BA, McDowell JE. Common neural circuitry supporting volitional saccades and its disruption in schizophrenia patients and relatives. Biol Psychiatry (2008) 64:1042-50. doi:10.1016/ j.biopsych.2008.06.015

156. van Os J, Kenis G, Rutten BP. The environment and schizophrenia. Nature (2010) 468:203-12. doi:10.1038/nature09563

157. Soliman A, O’Driscoll GA, Pruessner J, Joober R, Ditto B, Streicker E, et al. Limbic response to psychosocial stress in schizotypy: a functional magnetic resonance imaging study. Schizophr Res (2011) 131:184-91. doi:10.1016/j.schres. 2011.05.016

158. Soliman A, O’Driscoll GA, Pruessner J, Holahan AL, Boileau I, Gagnon $\mathrm{D}$, et al. Stress-induced dopamine release in humans at risk of psychosis: a [11C]raclopride PET study. Neuropsychopharmacology (2008) 33:2033-41. doi:10.1038/sj.npp.1301597

159. Greicius M. Resting-state functional connectivity in neuropsychiatric disorders. Curr Opin Neurol (2008) 21:424-30. doi:10.1097/WCO. 0b013e328306f2c5

160. Koenigsberg HW, Buchsbaum MS, Buchsbaum BR, Schneiderman JS, Tang CY, New A, et al. Functional MRI of visuospatial working memory in schizotypal personality disorder: a region-of-interest analysis. Psychol Med (2005) 35:1019-30. doi:10.1017/S0033291705004393

161. Dickey CC, Morocz IA, Niznikiewicz MA, Voglmaier M, Toner S, Khan U, et al. Auditory processing abnormalities in schizotypal personality disorder: an fMRI experiment using tones of deviant pitch and duration. Schizophr Res (2008) 103:26-39. doi:10.1016/j.schres.2008.04.041

162. Dickey CC, Morocz IA, Minney D, Niznikiewicz MA, Voglmaier MM, Panych LP, et al. Factors in sensory processing of prosody in schizotypal personality disorder: an fMRI experiment. Schizophr Res (2010) 121:75-89. doi:10.1016/j. schres.2010.03.008

163. Haenschel C, Bittner RA, Haertling F, Rotarska-Jagiela A, Maurer K, Singer W, et al. Contribution of impaired early-stage visual processing to working memory dysfunction in adolescents with schizophrenia: a study with event-related potentials and functional magnetic resonance imaging. Arch Gen Psychiatry (2007) 64:1229-40. doi:10.1001/archpsyc.64.11.1229

164. Klein C, Berg P, Rockstroh B, Andresen B. Topography of the auditory P300 in schizotypal personality. Biol Psychiatry (1999) 45:1612-21. doi:10.1016/S00063223(98)00254-6

165. Winterer G, Goldman D. Genetics of human prefrontal function. Brain Res Brain Res Rev (2003) 43:134-63. doi:10.1016/S0165-0173(03)00205-4

166. Prévost M, Rodier M, Renoult L, Kwann Y, Dionne-Dostie E, Chapleau I, et al. Schizotypal traits and N400 in healthy subjects. Psychophysiology (2010) 47:1047-56. doi:10.1111/j.1469-8986.2010.01016.x

167. Koychev I, Deakin JF, Haenschel C, El-Deredy W. Abnormal neural oscillations in schizotypy during a visual working memory task: support for a deficient top-down network? Neuropsychologia (2011) 49:2866-73. doi:10.1016/j. neuropsychologia.2011.06.012

168. Mohr C, Blanke O, Brugger P. Perceptual aberrations impair mental own-body transformations. Behav Neurosci (2006) 120:528-34. doi:10.1037/0735-7044. 120.3.528

169. Croft RJ, Lee A, Bertolot J, Gruzelier JH. Associations of P50 suppression and desensitization with perceptual and cognitive features of "unreality" in schizotypy. Biol Psychiatry (2001) 50:441-6. doi:10.1016/S0006-3223(01)01082-4

170. Wang J, Miyazato H, Hokama H, Hiramatsu K, Kondo T. Correlation between P50 suppression and psychometric schizotypy among non-clinical Japanese subjects. Int J Psychophysiol (2004) 52:147-57. doi:10.1016/j.ijpsycho. 2003.06.001

171. Evans LH, Gray NS, Snowden RJ. Reduced P50 suppression is associated with the cognitive disorganisation dimension of schizotypy. Schizophr Res (2007) 97:152-62. doi:10.1016/j.schres.2007.07.019

172. Cadenhead KS, Light GA, Geyer MA, Braff DL. Sensory gating deficits assessed by the P50 event-related potential in subjects with schizotypal personality disorder. Am J Psychiatry (2000) 157:55-9.

173. Clementz BA, Geyer MA, Braff DL. Poor P50 suppression among schizophrenia patients and their first-degree biological relatives. Am J Psychiatry (1998) 155:1691-4. 
174. Platek SM, Fonteyn LC, Izzetoglu M, Myers TE, Ayaz H, Li C, et al. Functional near infrared spectroscopy reveals differences in self-other processing as a function of schizotypal personality traits. Schizophr Res (2005) 73:125-7. doi:10.1016/j.schres.2004.09.024

175. Hori H, Ozeki Y, Terada S, Kunugi H. Functional near-infrared spectroscopy reveals altered hemispheric laterality in relation to schizotypy during verbal fluency task. Prog Neuropsychopharmacol Biol Psychiatry (2008) 32:1944-51. doi:10.1016/j.pnpbp.2008.09.019

176. Hori H, Nagamine M, Soshi T, Okabe S, Kim Y, Kunugi H. Schizotypal traits in healthy women predict prefrontal activation patterns during a verbal fluency task: a near-infrared spectroscopy study. Neuropsychobiology (2008) 57:61-9. doi:10.1159/000129669

177. Breier A, Su TP, Saunders R, Carson RE, Kolachana BS, de Bartolomeis A, et al. Schizophrenia is associated with elevated amphetamine-induced synaptic dopamine concentrations: evidence from a novel positron emission tomography method. Proc Natl Acad Sci U S A (1997) 94:2569-74. doi:10.1073/pnas.94.6.2569

178. Laruelle M, Abi-Dargham A, Gil R, Kegeles L, Innis R. Increased dopamine transmission in schizophrenia: relationship to illness phases. Biol Psychiatry (1999) 46:56-72. doi:10.1016/S0006-3223(99)00067-0

179. Abi-Dargham A, Kegeles LS, Zea-Ponce Y, Mawlawi O, Martinez D, Mitropoulou V, et al. Striatal amphetamine-induced dopamine release in patients with schizotypal personality disorder studied with single photon emission computed tomography and [123I] iodobenzamide. Biol Psychiatry (2004) 55:1001-6. doi:10.1016/j.biopsych.2004.01.018

180. Woodward ND, Cowan RL, Park S, Ansari MS, Baldwin RM, Li R, et al. Correlation of individual differences in schizotypal personality traits with amphetamine-induced dopamine release in striatal and extrastriatal brain regions. Am J Psychiatry (2011) 168:418-26. doi:10.1176/appi.ajp.2010. 10020165

181. Koychev I, McMullen K, Lees J, Dadhiwala R, Grayson L, Perry C, et al. A validation of cognitive biomarkers for the early identification of cognitive enhancing agents in schizotypy: a three-center double-blind placebo-controlled study. Eur Neuropsychopharmacol (2012) 22:469-81. doi:10.1016/j.euroneuro.2011. 10.005

182. Schmechtig A, Lees J, Grayson L, Craig KJ, Dadhiwala R, Dawson GR, et al. Effects of risperidone, amisulpride and nicotine on eye movement control and their modulation by schizotypy. Psychopharmacology (Berl) (2013) 227:331-45. doi:10.1007/s00213-013-2973-4

183. Burke JG, Reveley MA. Improved antisaccade performance with risperidone in schizophrenia. J Neurol Neurosurg Psychiatry (2002) 72:449-54.

184. Harris MS, Reilly JL, Keshavan MS, Sweeney JA. Longitudinal studies of antisaccades in antipsychotic-naive first-episode schizophrenia. Psychol Med (2006) 36:485-94. doi:10.1017/S0033291705006756

185. Debruille JB, Rodier M, Prévost M, Lionnet C, Molavi S. Effects of a small dose of olanzapine on healthy subjects according to their schizotypy: an ERP study using a semantic categorization and an oddball task. Eur Neuropsychopharmacol (2013) 23:339-50. doi:10.1016/j.euroneuro.2012.06.005

186. Condray R, Steinhauer SR, Cohen JD, van Kammen DP, Kasparek A. Modulation of language processing in schizophrenia: effects of context and haloperidol on the event-related potential. Biol Psychiatry (1999) 45:1336-55. doi:10.1016/S0006-3223(98)00317-5

187. Condray R, Siegle GJ, Cohen JD, van Kammen DP, Steinhauer SR. Automatic activation of the semantic network in schizophrenia: evidence from eventrelated brain potentials. Biol Psychiatry (2003) 54:1134-48. doi:10.1016/S00063223(03)00699-1

188. Nothen MM, Nieratschker V, Cichon S, Rietschel M. New findings in the genetics of major psychoses. Dialogues Clin Neurosci (2010) 12:85-93.

189. Brune M. Schizophrenia-an evolutionary enigma? Neurosci Biobehav Rev (2004) 28:41-53. doi:10.1016/j.neubiorev.2003.10.002

190. Esterberg ML, Compton MT. The psychosis continuum and categorical versus dimensional diagnostic approaches. Curr Psychiatry Rep (2009) 11:179-84. doi:10.1007/s11920-009-0028-7

191. Larrison AL, Briand KA, Sereno AB. Nicotine, caffeine, alcohol and schizotypy. Pers Individ Diff (1999) 27:101-8. doi:10.1016/S0191-8869(98)00217-7

192. Williams JH, Wellman NA, Rawlins JN. Tobacco smoking correlates with schizotypal and borderline personality traits. Pers Individ Diff (1996) 20:267-70. doi:10.1016/0191-8869(95)00179-4
193. Williams JH, Wellman NA, Rawlins JN. Cannabis use correlates with schizotypy in healthy people. Addiction (1996) 91:869-77. doi:10.1111/j.1360-0443. 1996.tb03581.x

194. Fridberg DJ, Vollmer JM, O’Donnell BF, Skosnik PD. Cannabis users differ from non-users on measures of personality and schizotypy. Psychiatry Res (2011) 186:46-52. doi:10.1016/j.psychres.2010.07.035

195. Kwapil TR, Brown LH, Silvia PJ, Myin-Germeys I, Barrantes-Vidal N. The expression of positive and negative schizotypy in daily life: an experience sampling study. Psychol Med (2012) 42:2555-66. doi:10.1017/S0033291712000827

196. Lewandowski KE, Barrantes-Vidal N, Nelson-Gray RO, Clancy C, Kepley HO, Kwapil TR. Anxiety and depression symptoms in psychometrically identified schizotypy. Schizophr Res (2006) 83:225-35. doi:10.1016/j.schres. 2005.11.024

197. Seghers JP, McCleery A, Docherty NM. Schizotypy, alexithymia, and socioemotional outcomes. J Nerv Ment Dis (2011) 199:117-21. doi:10.1097/NMD. 0b013e3182083bc4

198. Berenbaum H, Valera EM, Kerns JG. Psychological trauma and schizotypal symptoms. Schizophr Bull (2003) 29:143-52. doi:10.1093/oxfordjournals. schbul.a006985

199. Martin EA, Bailey DH, Cicero DC, Kerns JG. Social networking profile correlates of schizotypy. Psychiatry Res (2012) 200:641-6. doi:10.1016/j.psychres. 2012.06.031

200. Addington J, Cornblatt BA, Cadenhead KS, Cannon TD, McGlashan TH, Perkins DO, et al. At clinical high risk for psychosis: outcome for nonconverters. Am J Psychiatry (2011) 168:800-5. doi:10.1176/appi.ajp.2011.10081191

201. Blanchard JJ, Collins LM, Aghevli M, Leung WW, Cohen AS. Social anhedonia and schizotypy in a community sample: the Maryland longitudinal study of schizotypy. Schizophr Bull (2011) 37:587-602. doi:10.1093/schbul/ sbp 107

202. Fonseca-Pedrero E, Paino M, Lemos-Giraldez S, Muniz J. Schizotypal traits and depressive symptoms in nonclinical adolescents. Compr Psychiatry (2011) 52:293-300. doi:10.1016/j.comppsych.2010.07.001

203. Henry JD, Bailey PE, Rendell PG. Empathy, social functioning and schizotypy. Psychiatry Res (2008) 160:15-22. doi:10.1016/j.psychres.2007.04.014

204. Jahshan CS, Sergi MJ. Theory of mind, neurocognition, and functional status in schizotypy. Schizophr Res (2007) 89:278-86. doi:10.1016/j.schres.2006.09.004

205. Aguirre F, Sergi MJ, Levy CA. Emotional intelligence and social functioning in persons with schizotypy. Schizophr Res (2008) 104:255-64. doi:10.1016/j. schres.2008.05.007

206. Barrantes-Vidal N, Lewandowski KE, Kwapil TR. Psychopathology, social adjustment and personality correlates of schizotypy clusters in a large nonclinical sample. Schizophr Res (2010) 122:219-25. doi:10.1016/j.schres. 2010.01 .006

207. Thaker G, Adami H, Gold J. Functional deterioration in individuals with schizophrenia spectrum personality symptoms. J Pers Disord (2001) 15:229-34. doi:10.1521/pedi.15.3.229.19207

208. Cohen AS, Davis TE III. Quality of life across the schizotypy spectrum: findings from a large nonclinical adult sample. Compr Psychiatry (2009) 50:408-14 doi:10.1016/j.comppsych.2008.11.002

209. Koychev I, Barkus E, Ettinger U, Killcross S, Roiser JP, Wilkinson L, et al. Evaluation of state and trait biomarkers in healthy volunteers for the development of novel drug treatments in schizophrenia. J Psychopharmacol (2011) 25:1207-25. doi: $10.1177 / 0269881111414450$

210. Dourish CT, Dawson GR. Precompetitive consortium approach to validation of the next generation of biomarkers in schizophrenia. Biomark Med (2014) 8:5-8. doi:10.2217/bmm.13.89

211. Kraemer HC, Noda A, O’Hara R. Categorical versus dimensional approaches to diagnosis: methodological challenges. J Psychiatr Res (2004) 38:17-25. doi:10.1016/S0022-3956(03)00097-9

212. Markon KE, Chmielewski M, Miller CJ. The reliability and validity of discrete and continuous measures of psychopathology: a quantitative review. Psychol Bull (2011) 137:856-79. doi:10.1037/a0023678

213. Kety SS. Mental illness in the biological and adoptive relatives of schizophrenic adoptees: findings relevant to genetic and environmental factors in etiology. Am J Psychiatry (1983) 140:720-7.

214. Gottesman II, Gould TD. The endophenotype concept in psychiatry: etymology and strategic intentions. Am J Psychiatry (2003) 160:636-45. doi:10.1176/ appi.ajp.160.4.636 
215. Meyer-Lindenberg A, Weinberger DR. Intermediate phenotypes and genetic mechanisms of psychiatric disorders. Nat Rev Neurosci (2006) 7:818-27. doi:10.1038/nrn1993

216. Fusar-Poli P, Borgwardt S, Bechdolf A, Addington J, Riecher-Rössler A, Schultze-Lutter F, et al. The psychosis high-risk state: a comprehensive state-of-the-art review. JAMA Psychiatry (2013) 70:107-20. doi:10.1001/ jamapsychiatry.2013.269

217. Chapman LJ, Chapman JP, Kwapil TR, Eckblad M, Zinser MC. Putatively psychosis-prone subjects 10 years later. J Abnorm Psychol (1994) 103:171-83. doi:10.1037/0021-843X.103.2.171

218. Barrantes-Vidal N, Gross GM, Sheinbaum T, Mitjavila M, Ballespí S, Kwapil TR. Positive and negative schizotypy are associated with prodromal and schizophrenia-spectrum symptoms. Schizophr Res (2013) 145:50-5. doi:10. 1016/j.schres.2013.01.007

219. Lin A, Wigman JT, Nelson B, Wood SJ, Vollebergh WA, van Os J, et al. Followup factor structure of schizotypy and its clinical associations in a help-seeking sample meeting ultra-high risk for psychosis criteria at baseline. Compr Psychiatry (2013) 54:173-80. doi:10.1016/j.comppsych.2012.06.011
Conflict of Interest Statement: The authors declare that the research was conducted in the absence of any commercial or financial relationships that could be construed as a potential conflict of interest.

Received: 27 November 2013; paper pending published: 13 December 2013; accepted: 06 February 2014; published online: 21 February 2014.

Citation: Ettinger U, Meyhöfer I, Steffens M, Wagner M and Koutsouleris N (2014) Genetics, cognition, and neurobiology of schizotypal personality: a review of the overlap with schizophrenia. Front. Psychiatry 5:18. doi: 10.3389/fpsyt.2014.00018

This article was submitted to Neuropsychiatric Imaging and Stimulation, a section of the journal Frontiers in Psychiatry.

Copyright (C) 2014 Ettinger, Meyhöfer, Steffens, Wagner and Koutsouleris. This is an open-access article distributed under the terms of the Creative Commons Attribution License (CC BY). The use, distribution or reproduction in other forums is permitted, provided the original author(s) or licensor are credited and that the original publication in this journal is cited, in accordance with accepted academic practice. No use, distribution or reproduction is permitted which does not comply with these terms. 